\title{
PROGRAMA PARA GERAÇÃO DE PROJETOS ARQUITETÔNICOS DE UNIDADE DE TRATAMENTO DE ÁGUA
}

\author{
Rafael Montanhini Soares de Oliveira ${ }^{1}$ \\ Dominique Martins Sala ${ }^{2}$ \\ Muriel BuzoSozim ${ }^{3}$ \\ Daniel Ferreira Tomaz ${ }^{4}$
}

\begin{abstract}
RESUMO
Será abordado nesse trabalho o desenvolvimento de um sistema computacional de prédimensionamento das unidades de floculação, decantação e filtração de uma ETA que possa gerar imagens com as dimensões calculadas e que essas imagens possam ser transferidas automaticamente para o software AutoCAD. Desta forma as imagens podem futuramente ser utilizadas para cálculos de estrutura das unidades de tratamento dando auxílio ao projetista em uma etapa inicial de projeto e ao estudante que tenha interesse na área. Com a geração deste programa pretende-se através do computador habilitar o acadêmico a desenvolver projetos de sistemas de tratamento com maior segurança e confiança. O programa desenvolvido sistema computacional de pré-dimensionamento das unidades de floculação, decantação e filtração de uma ETA, está sendo elaborado e gerando resultados bastante promissores.
\end{abstract}

PALAVRAS-CHAVE:Dimensionamento de ETA, Python, AutoCAD.

\section{PROGRAM FOR ARCHITECTURAL PROJECT GENERATION OF WATER TREATMENT UNIT}

\begin{abstract}
It will be approached that the development work of a computer system to pre - flocculation of the sizing units, decantation and filtration of an ETA that may generate images with the calculated dimensions and these images can be automatically transferred to the AutoCAD software. Thus the images can further be used to structure calculations of treatment units giving aid to the designer at a nearly stage of project and the student who has an interest in the area. With the generation of this program is intended through the computer to enable the students to develop treatment systems projects with greater security and confidence. The program developed computational system
\end{abstract}

\footnotetext{
${ }^{1}$ Doutor em Engenharia Química, UTFPR, Professor. rafaeloliveira@utfpr.edu.br.

${ }^{2}$ Acadêmica do Curso de Engenharia Ambiental, UTFPR. dominique22@gmail.com.

${ }^{3}$ Acadêmico do Curso de Ciência da Computação, UTFPR. muriel23@gmail.com.

${ }^{4}$ Acadêmico do Curso de Engenharia Ambiental, UTFPR. tomaz.danfer@gmail.com.
} 


\section{Periódica Eletrônica

\section{PROGRAMA PARA LA GENERACIÓN DE PROYECTO ARQUITECTÓNICO DE LA UNIDAD DE TRATAMIENTO DE AGUA}

\section{RESUMEN}

Se acercó a que el trabajo de desarrollo de un sistema informático para pre - floculación de lãs unidades de tamaño, decantación y filtración de una ETA que pueden generar imágenes com las dimensiones calculadas y estas imágenes se pueden transferir automáticamente al software AutoCAD. Así, lãs imágenes se pueden usar además de estructurar cálculos de unidades de tratamiento que Dan ayuda al diseñadoren una etapa temprana Del proyecto y el estudiante que tiene um interes em la zona. Com La generación de este programa se pretende a través de La computadora para permitir a los estudiantes a desarrollar proyectos de sistemas de tratamiento com mayor seguridad y confianza. El programa desarrollado sistema de diseño preliminar de cálculo de las unidades de floculación, sedimentación y filtración de ETA, está siendo preparado y generando resultados muy prometedores.

PALABRAS CLAVE: dimensiones ETA, Python, AutoCad.

\section{INTRODUÇÃO}

A história do tratamento da água continua sendo descoberta, porém há evidências de que desde os tempos antigos já havia uma preocupação com a qualidade da água a ser consumida. Os antigos egípcios armazenavam a água em grandes jarros e deixavam que as impurezas sedimentassem no fundo dos mesmos. Hipócrates, na Grécia, considerado o Pai da Medicina, aconselhava a ferver a água antes de bebê-la.

O primeiro sistema de abastecimento público foi desenvolvido por John Gibb, em1804, em Paisley, na Escócia. Em 1806, uma grande estação de tratamento de água começou a operar em Paris, na França. Nesta, a água era armazenada para sedimentação por 12 horas sendo posteriormente filtrada por filtros de areia e carvão.

Apenas na década de 1870, Dr. Robert Koche Dr. Joseph Lister demonstraram que os microorganismos presentes na água podem causar doenças. Em1902, em Middlekerk, na Bélgica, tem-se o primeiro registro de utilização do cloro para desinfecção (WATER RESEARCH COMISSION,2009).

Segundo DiBernardo e Dantas (2005), estima-seque, no Brasil, cerca de $60 \%$ das hospitalizações estejam relacionadas às deficiências do saneamento 
básico, causando conseqüências de impacto extremamente negativo na qualidade e expectativa de vida da população. As informações coletadas pela Pesquisa Nacional de Saneamento Básico - PNSB 2008 -, sobre abastecimento de água revelam que dos 5.564 municípios brasileiros existentes em 2008, 5.531 (99,4\%) realizavam abastecimento de água por rede geral de distribuição em pelo menos um distrito ou parte dele.

O projeto de uma Estação de Tratamento de Água (ETA) é elaborado através de um amplo estudo das características da comunidade a ser abastecida e das propriedades ambientais da região. Estes estudos têm como objetivo levantar possibilidades técnico - econômicas viáveis. Os estudos preliminares essenciais, segundo Castro (2008a), são:

a) Características dos mananciais;

b) População a ser atendida;

c) Variações de demanda;

d) Clima local;

e) Atividades econômicas da cidade;

f) Características sócio-culturais da população.

O processo de tratamento utilizado na maior parte das Estações de Tratamento de Água (ETA) no Brasil é denominado tratamento convencional. Este processo consiste em, a partir da análise da água bruta que é aduzida, encaminhála para o processo de coagulação na unidade de mistura rápida. Após, é conduzida para o processo de floculação na unidade de mistura lenta e, em seguida, entra no processo de decantação, no chamado decantador. Após estes processos a água segue para o filtro, sendo em seguida desinfetada. Caso haja necessidade, seu $\mathrm{pH}$ é ajustado na etapa de pós-alcalinização e, por fim, fluoretada.

Os processos que constituem as etapas de uma ETA podem ser apresentados conforme esquema da figura1. 
Figura1:esquema das etapas de tratamento convencional em uma ETA

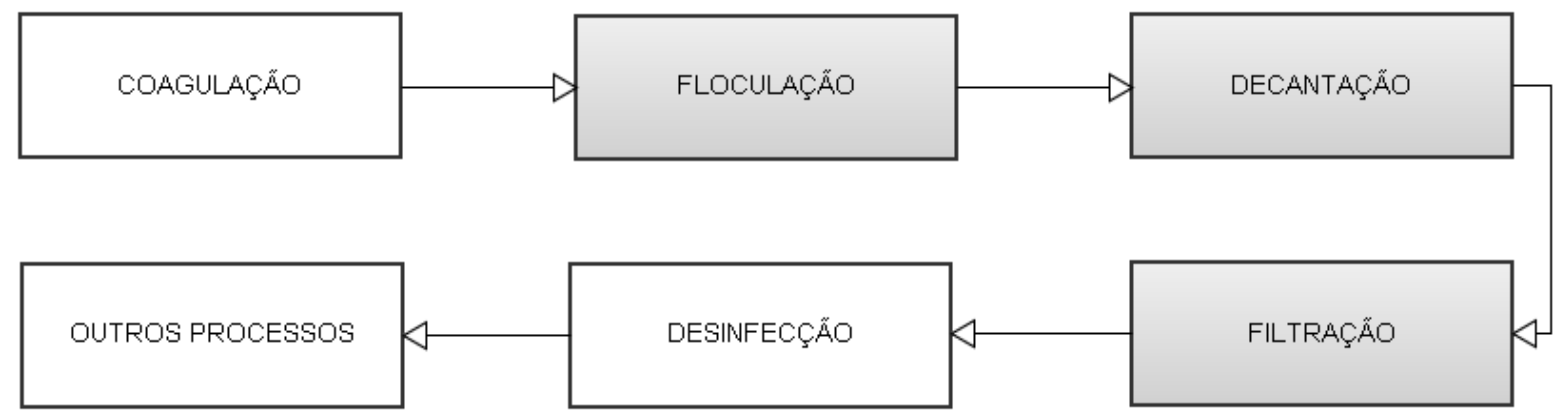

Neste trabalho serão estudados, conforme destacado na figura 1, exclusivamente os processos de floculação, decantação e filtração, pois estes consistem em maior demanda de tempo para o projetista no momento do dimensionamento das unidades que compõem o tratamento de água convencional. Como resultado final será obtido um software, acessível que a partir de dados de entrada do usuário realize o dimensionamento das unidades citadas anteriormente. O programa irá fornecer um arquivo de coordenadas que poderão ser utilizadas no software AutoCAD gerando uma imagem da unidade dimensionada.Este trabalho busca desenvolver uma ferramenta de auxílio ao projetista em uma etapa inicial de projeto e ao estudante que tenha interesse na área.

\section{OBJETIVOS}

O objetivo principal desse trabalho e o desenvolvimento de um sistema computacional de pré-dimensionamento das unidades de floculação, decantação e filtração de uma ETA que possa gerar imagens com as dimensões calculadas e que essas imagens possam ser transferidas automaticamente para o software AutoCAD. Desta forma as imagens podem futuramente ser utilizadas para cálculos de estrutura das unidades de tratamento.

Com a geração deste programa pretende-se através do computador habilitar o acadêmico a desenvolver projetos de sistemas de tratamento com maior segurança e confiança. 


\title{
METODOLOGIA
}

Nessa primeira etapa do programa foi desenvolvido o software para cálculo do dimensionamento e geração de imagem da unidade de decantação de uma Estação de Tratamento de Água.

$O$ projeto foi desenvolvido em linguagem Python, por um acadêmico do curso de Ciência da Computação da UTFPR - Campo Mourão. Segue abaixo o código utilizado para a geração do programa.

\author{
\#!/usr/bin/python \\ \# -*- coding: cp1252 -* \\ frommathimport* \\ defcalarea $(Q)$ :

$$
\text { As }=(Q * 86400) / q
$$ \\ print "As = ", (As), "m" \\ return As
}

deftempodetencao(As, Q):

print "InVerificação do tempo de detenção hidráulico"

$\mathrm{h}=$ input ("Digite a altura: ")

$\operatorname{tdh}=\left(A s^{*} h\right) /(Q * 3600)$

print "tdh = ", (tdh), "horas"

return $\mathrm{h}$

defdefgeometriaB(As):

print "InDedinição da geometria do decantador"

$B=A s / 4$

$$
B=\operatorname{sqrt}(B)
$$

print "B = ", B, "m"

return $B$

defdefgeometriaL(B): 
$L=4$ * $B$

print "L = ", L, "m"

return $L$

defescoamentosup(B, L, Q):

print "InVerificação da taxa de escoamento superficial"

As $=B * L$

$q=(Q * 86400) / A s$

print "q = ", (q), "m³/m²/dia"

defvelocidadehoriz( $Q, h, B)$ :

print "\nCálculo da velocidade horizontal"

Af $=h{ }^{*} B$

$\mathrm{Vh}=\mathrm{Q} / \mathrm{Af}$

$\mathrm{Vh}=\mathrm{Vh}{ }^{*} 100$

print "Vh = ", Vh, "cm/s"

returnVh

defraiohidraulico(B, $h)$ :

print "\nCálculo do raio hidráulico"

$R h=(B * h) /\left(B+2{ }^{*} h\right)$

print "Rh = ", Rh, "m"

return $\mathrm{Rh}$

defnumReynolds(Vh, Rh):

print "\nCálculo do número de Reynolds"

$\mathrm{Vh}=\mathrm{Vh} / 100$

$$
\mathrm{Re}=\left(\mathrm{Vh}{ }^{*} \mathrm{Rh}\right) /(0.000001)
$$

print "Re = ", Re

defdimensionamentocalhas $(h, q)$ :

print "\nDimensionamento das calhas de coleta de água decantada"

$q \mathrm{l}=0.018 * h * q$ 
print "ql<= ", ql, "l/s/m"

returnql

defcomprimentototal(ql, Q):

print "\nComprimento total de vertedores"

$Q=Q * 1000$

$\mathrm{Lv}=\mathrm{Q} / \mathrm{ql}$

print "Lv = ", Lv, "m"

returnLv

defcompcalha(L):

print "InComprimento da Calha"

$L c=L$ * 0.2

$L C=\operatorname{round}(L c, 2)+0.01$

print "Lc = ", Lc, "m"

returnLc

defnumcalhas(Lv, Lc):

print "InNumero de Calhas"

$\mathrm{N}=\mathrm{Lv} /(2$ * Lc)

print N, "Calhas de ", Lc, "m"

return $\mathrm{N}$

defespcalhas $(B, N)$ :

print "In Espaçamento entre as calhas"

$$
\mathrm{E}=\mathrm{B} / \mathrm{N}
$$

print "E = ", E, "m"

if __name__ $==$ "_ main__ $"$ :

print "Dimensionamento de decantador convencional"

print "Calculo da área"

$$
\mathrm{Q}=\text { input ("Digite o valor da Vazão: ") }
$$

q = input ("Digite o valor da Taxa de Aplicação: ") 


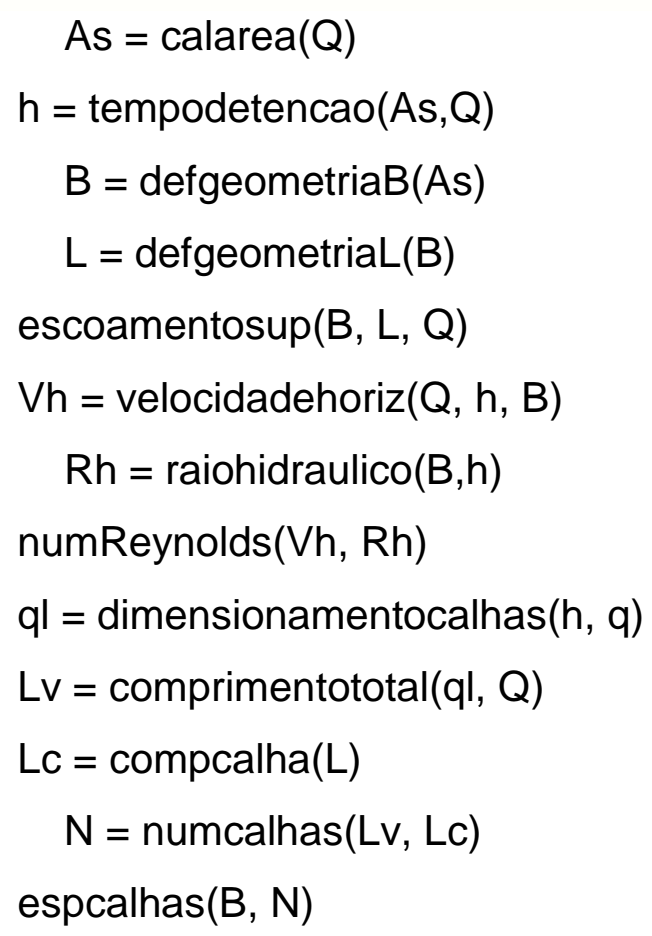

Os detalhes dos cálculos utilizados para o dimensionamento das unidades de tratamento de água foram desenvolvidos por acadêmicos dos cursos de Engenharia Civil e Engenharia Ambiental da UTFPR - Campo Mourão. Seguem abaixo os cálculos utilizados nessa primeira etapa.

Cálculo da área do decantador:

$$
V_{S}=q=\frac{Q}{A_{S}}
$$

Onde:

$\mathrm{q}=$ taxa de aplicação

$Q=$ vazão

As $=$ área do decantador

$\mathrm{V}_{\mathrm{s}}=$ volume do decantador

Cálculo do tempo de detenção hidráulico:

$$
\theta_{h}=\frac{V_{d e c}}{Q}
$$

Admitindo uma relação entre $L / B$ igual a 4:

$$
A_{S}=B \cdot L=4 \cdot B^{2}
$$

Verificação da taxa de escoamento superficial: 


$$
q=\frac{Q}{A_{S}}
$$

Cálculo da velocidade horizontal:

$$
V_{h}=\frac{Q}{A_{h}}
$$

Obs - a profundidade do tanque é adotada pelo projetista, em média $5 \mathrm{~m}$.

Cálculo do Raio Hidráulico:

$$
R_{h}=\frac{B \cdot h}{(B+2 . h)}
$$

Cálculo do Número de Reynolds:

$$
R_{e}=\frac{V_{h} \cdot R_{h}}{v}
$$

Dimensionamento das calhas de coleta de água decantada:

$$
q_{l} \leq 0,018 . H . q
$$

Cálculo do comprimento total de vertedor:

$$
q_{l}=\frac{Q}{L_{v}}
$$

Cálculo do número de calhas:

$$
N_{\text {calhas }}=\frac{L_{v}}{2 \cdot L_{\text {calha }}}
$$

\section{RESULTADOS}

As telas abaixo demonstram as perguntas iniciais feitas pelo programa sobre os parâmetros necessários para os início dos cálculos. 
Figura 2: tela do programa solicitando que o usuário digite o valor da vazão

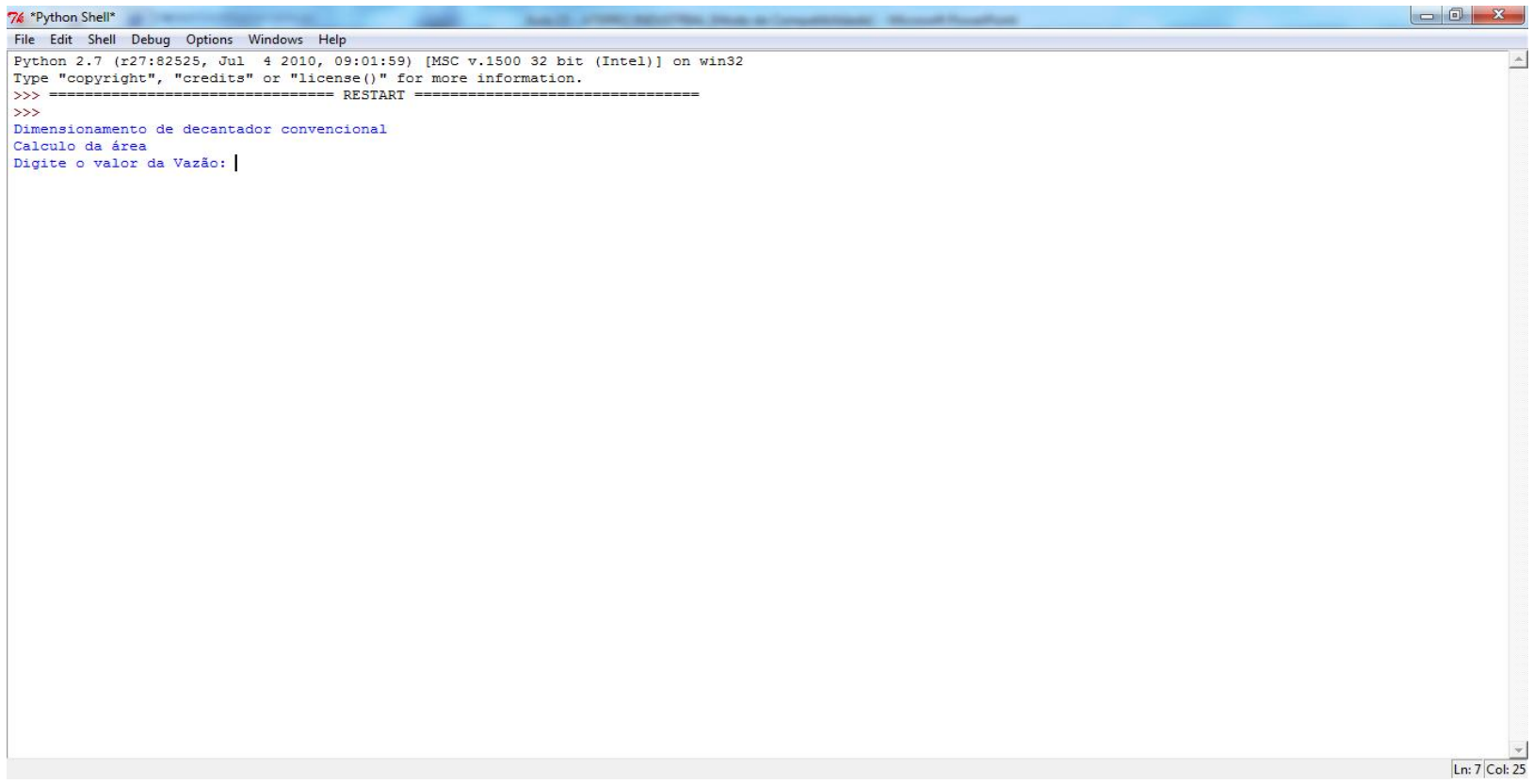

Figura 3: tela do programa solicitando que o usuário digite o valor da taxa de aplicação

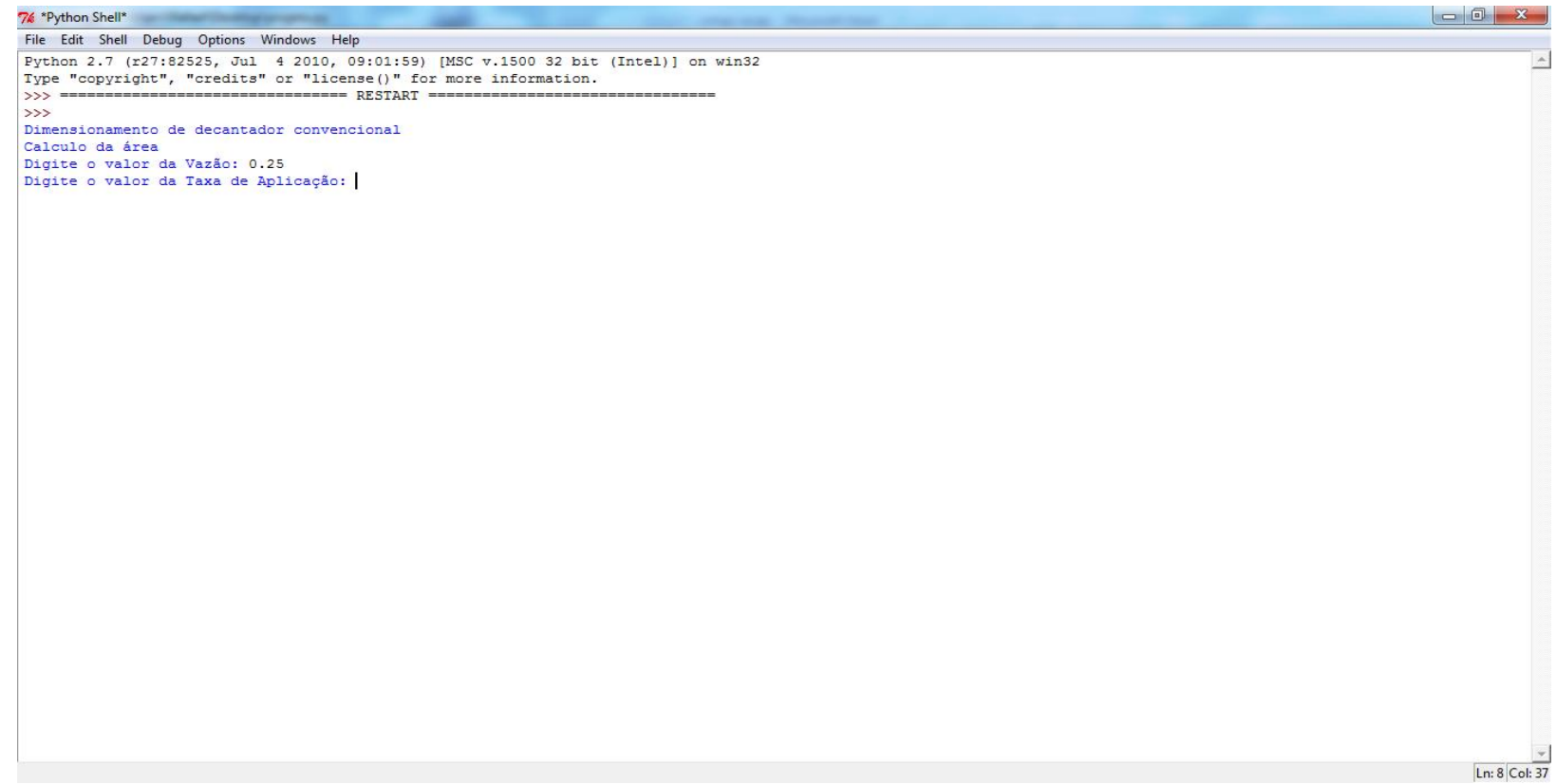


Figura 4: tela do programa solicitando que o usuário digite a altura do decantador

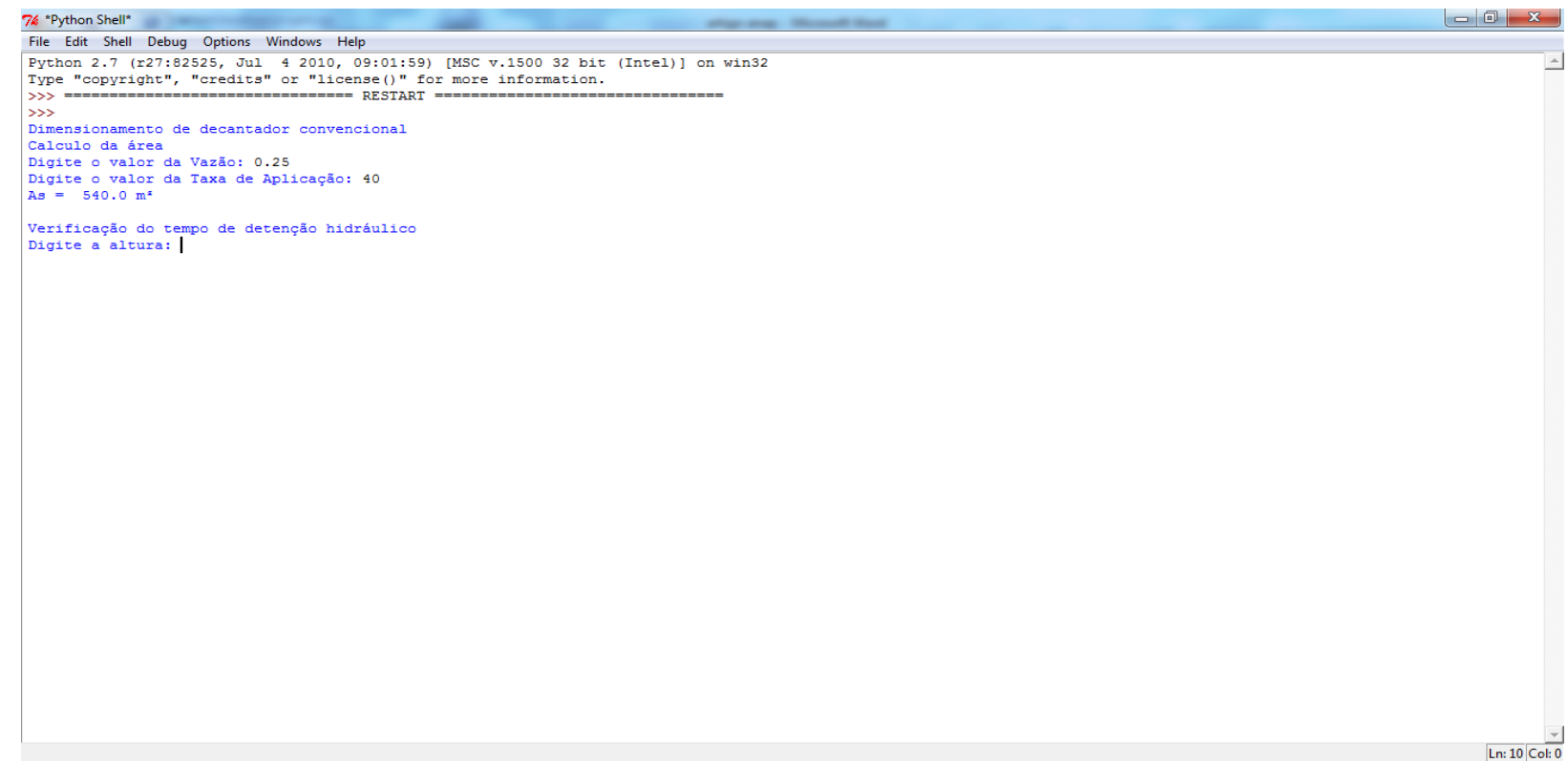

Depois de respondidas as perguntas inicias o programa calcula: o tempo de detenção, a geometria do decantador, a verificação da taxa de escoamento superficial, o cálculo da velocidade horizontal, o cálculo do raio hidráulico, o cálculo do número de Reynolds, o dimensionamento das calhas de coleta de água decantada, o comprimento total de vertedores, o comprimento da Calha, o Número de Calhas e o espaçamento entre as calhas.

Figura 5: tela do programa com a apresentação dos resultados

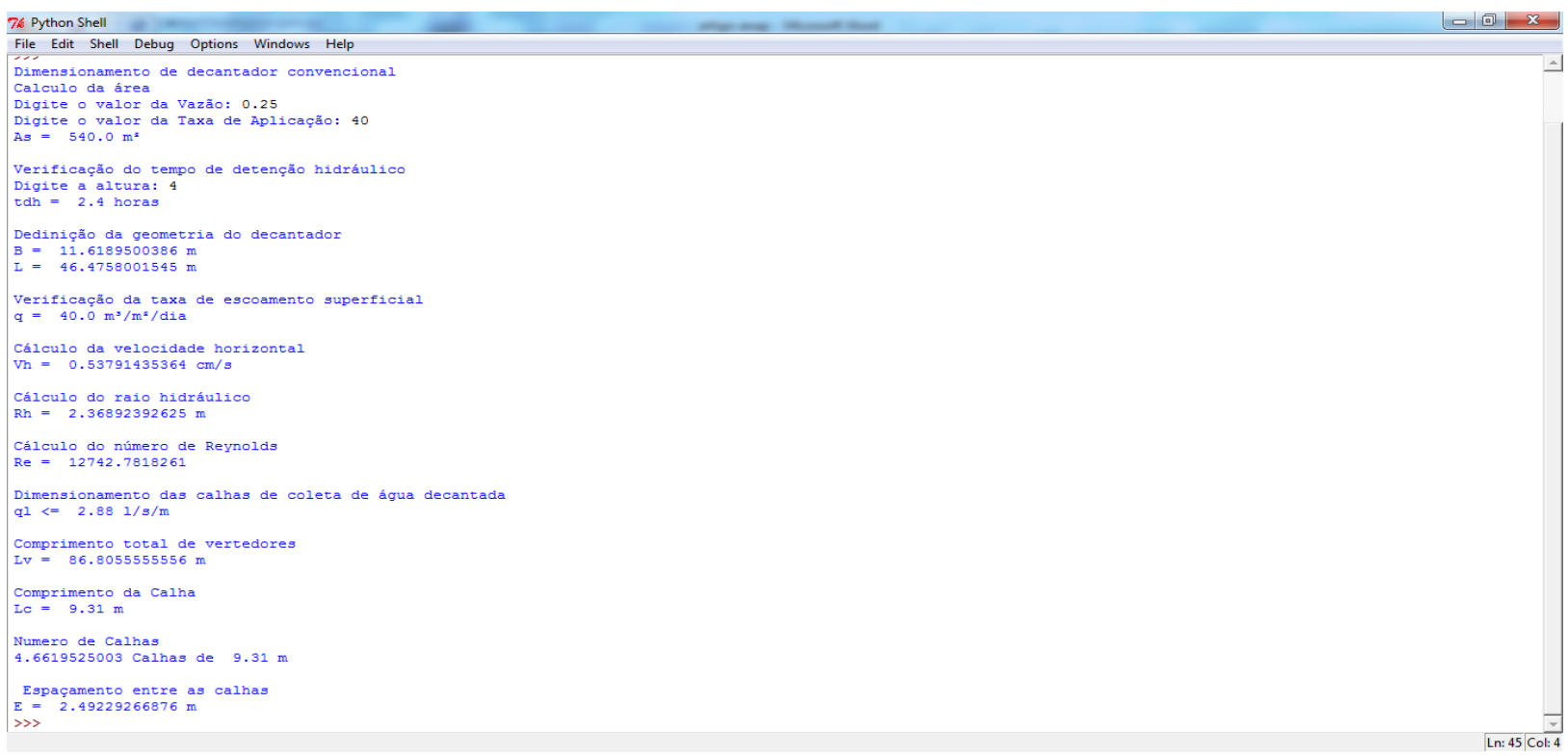


Os resultados são apresentados em uma única tela.

Após essa apresentação um arquivo com as coordenadas dos pontos para a geração de uma imagem no AutoCAD é salvo no programa bloco de notas. Esses pontos quando copiados para o programa AutoCAD podem ser abertos e gerar a imagem do decantador calculado anteriormente.

Esta imagem será testada em softwares para cálculo de estruturas compatíveis com imagens geradas no AutoCAD.

Até o momento o programa gera o tipo de resposta demonstrado na figura 5, uma interface mais amigável está sendo desenvolvida para facilitar a utilização pelo usuário e melhorar a apresentação dos resultados.

\section{CONCLUSÃO}

O programa desenvolvido sistema computacional de pré-dimensionamento das unidades de floculação, decantação e filtração de uma ETA, está sendo elaborado e gerando resultados bastante promissores. Além da possibilidade de geração de imagens para AutoCAD e cálculos estruturais a partir dessas imagens, o grande ganho é a apropriação dos conteúdos trabalhados para o desenvolvimento do programa por parte dos alunos envolvidos nesse projeto e os futuros acadêmicos que venham a utiliza-lo. Após as implementações da interface mais amigável o programa será utilizado na disciplina de gestão e tratamento de água da UTFPR - Campo Mourão.

\section{REFERÊNCIAS}

ACQUASANEQUIPAMENTOSPARATRATAMENTODEÁGUAEEFLUENTES.

Desenhofloculadormecânicodepaletasdeeixovertical.Disponívelem:<http://www.acquasan.com.br/sit e/equipamentos/floculador/des_palhetas.html>.Acessoem:1jul.2009

ASSOCIAÇÃOBRASILEIRADENORMASTÉCNICAS.NBR12216-projeto

de

estação

detratamentodeáguaparaabastecimentopúblico.RiodeJaneiro,1992. 


\section{Periádica Eletranica $\quad$ ISSN 1980-0827 \\ Fórum Ambiental \\ da Alta Paulista \\ Volume 11, Número 08, 2015 \\ Saúde e Saneamento Ambiental}

CASTRO,CarmenMariaBarrosde.Ponto1-AQualidadedaÁgua/Ponto

2IntroduçãoaoTratamentodaÁgua.PortoAlegre:GráficaUFRGS,2008a.

.Ponto3-CoagulaçãoeFloculação.PortoAlegre:GráficaUFRGS,2008b.

.Ponto4-Sedimentação/Decantação.PortoAlegre:GráficaUFRGS,2008c.

.Ponto5-Filtração.PortoAlegre:GráficaUFRGS,2008d.

DIBERNARDO,Luiz;DANTAS,AngelaDiBernardi.Métodosetécnicasdetratamentodeágua.2.ed.SãoP aulo:Rima,2005.

GEHLING,GinoRoberto.DesarrolloyAplicacióndeModelosEmpiricosparalaOperacióndeClarificaci ónPrimariadelasEDAR.1994.Tese(DoutoradoemEngenharia)

InstitutodeTecnologiayModelizaciónAmbiental,UniversidadePolitécnicadeCatalunya.

INSTITUTOBRASILEIRODEGEOGRAFIAEESTATÍSTICA.Pesquisa Nacional de Saneamento Básico. 2008.

Disponível

em:

<http://www.ibge.gov.br/home/presidencia/noticias/noticia_visualiza.php?id_noticia=1691\&id_pagina= 1>.Acessoem:20maio.2011.

LEME.FrancílioPaes.Teoriaetécnicasdetratamentodeágua.SãoPaulo:Cetesb,1979.

MELO,MarcosJoséVieiraDe.MedidasEstruturaiseNão-

estruturaisdeControledeEscoamentoSuperficialAplicáveisnaBaciadoRioFragosonaCidadedeOI inda.2007.173f.Tese(DoutoradoemEngenharia)-ProgramadePós-

GraduaçãoemEngenhariaCivil,UniversidadeFederaldePernambuco,Recife.Disponívelem:<http://www. bdtd.ufpe.br/tedeSimplificado//tde_busca/arquivo.php?codArquivo=3018>.Acessoem:25jun.2009.

RICHTER,CarlosAugusto;NETTO,JoséMartinianodeAzevedo.TratamentodeÁgua.SãoPaulo:EdgardB lücher,1991.

VIANNA,MarcosRocha.HidráulicaAplicadaàsEstaçõesdeTratamentodeÁgua.4.ed.BeloHorizonte:I mprimatur,2002.

WATERRESEARCHCOMISSION.HistoryofWaterTreatment.Disponívelem:

<http://www.wrc.org.za/downloads/education/History\%20of\%20water\%20treatment.pdf>.Acessoem:3j ul.2009. 